\title{
REABILITAÇÃO COM IMPLANTES APÓS ENXERTO ÓSSEO
}

Luis Francisco REIS, Sahara LITTIERI, Nicole Goissis MOTTI, Claudemar HEIZEN, Neblyssa Agatha SCHNEIDER

Enxertos ósseos autógenos são constituídos por uma matriz de tecido duro e um componente celular de osteoblasto, que expressam uma atividade osteogênica (GARCIA, 2000). Existem diferentes formas para sua aplicação, selecionadas conforme a indicação. Este trabalho tem como objetivo demonstrar a técnica para remoção de enxerto ósseo da região retro molar com a finalidade de devolver uma estrutura capaz de receber implantes dentários para a reabilitação bucal. O caso clínico que será apresentado é de uma paciente do gênero feminino com 35 anos e com ausência dos dentes 11 e 21 e perda óssea acentuada na região ântero superior. Embora o enxerto e o leito tenham contribuições individuais para o processo, é a soma de suas intenções que determinam o sucesso ou a falência do mesmo, (MORAES, 2002) e esta interação é mantida através da fixação rígida e da correta síntese dos tecidos para favorecer a proliferação capilar, garantindo suprimento de nutrientes e oxigênio e para que não haja a exposição do enxerto durante o período de integração. Concluiu-se que o tratamento com enxerto autógeno é uma alternativa para reabilitações de pacientes que apresentem reabsorções ósseas severas.

Palavras - chave: Enxerto ósseo; implante dentário; cirurgia bucal. 